\title{
El Catálogo General del Patrimonio Histórico Andaluz en las hoyas de Guadix y Baza
}

La comarca de Guadix y Baza está conformada por 48 municipios, de los cuales están afectados parcialmente 13. En este territorio nos encontramos 164 bienes patrimoniales inscritos en el Catálogo General del Patrimonio Histórico Andaluz (CGPHA). Si los clasificamos por la figura legal que les da protección, hay 162 Bienes de Interés Cultural (BIC) y 2 de Catalogación General.

\section{Bienes de Interés Cultural}

\begin{tabular}{lc}
\hline Tipología & Bienes \\
\hline Monumento & 143 \\
\hline${ }^{*}$ Arquitectura militar & 107 \\
\hline * Arte Rupestre & 7 \\
\hline Zona Arqueológica & 15 \\
\hline Conjunto Histórico & 3 \\
\hline Lugar de Interés Industrial & 1 \\
\hline Total & 162 \\
\hline
\end{tabular}

La ubicación de ambas comarcas en la confluencia de caminos, asi como la abundante riqueza de recursos naturales y minerales, ha favorecido el asentamiento humano desde los primeros homínidos, lo que contribuye de manera firme a la interpretación de la evolución humana en el sudeste peninsular, además de generar una abundancia de patrimonio defensivo a lo largo de todo el territorio (107 bienes de arquitectura militar).

Dentro del ingente patrimonio de arquitectura militar en la comarca destaca por su testimonio histórico y material la muralla de la sierra de Baza. Fue erigida por orden de Fernando el Católico durante el conflicto militar de la toma de Baza (1489), ciudad que por aquel entonces albergaba unos 20.000 habitantes. Las tropas castellanas habian establecido dos reales (campamentos) a las afueras de la ciudad, en concreto al noroeste y sureste de la población, y que se encontraban unidos por un foso, inundado tras el desvío de los cauces fluviales cercanos, y una fuerte empalizada con quince torres. Pero el asedio se postergaba por las numerosas incursiones de avituallamiento y escaramuzas que pasaban inadvertidas a través de la sierra al oeste y aún a pesar de haber levantado alli una torre vigía, que era incapaz de controlar la totalidad de la misma. Ante esto, el rey ordenó erigir una muralla de mampostería que atravesara toda la sierra. Diez mil soldados levantaron las defensas, de dos leguas de longitud según los textos' (entre ocho y diez kilómetros), y cuyas obras estuvieron concluidas en otoño de 1489, en un plazo de apenas dos o tres meses. Esta defensa fue determinante para la definitiva rendición de Baza el 28 de noviembre de ese mismo año. Poseian un adarve interior y unian los dos reales, si bien la parte reconocible en la actualidad es la que se representa en el plano adjunto, de unos 3.700 metros y no más de medio metro de altura, en parte debido al reaprovechamiento de su piedra por parte de las caleras que se sitúan a lo largo de todo su recorrido. Ello no evita que aún hoy sea identificable desde ortofotografía.

Entre los expedientes de protección que afectan al patrimonio andaluz en el área delimitada habría que destacar además otros por diferentes argumentos.

Las Minas de Alquife, expediente que se declaró Bien de Interés Cultural por Decreto 333/2010 de 13 de julio, es destacable no sólo por su amplitud territorial, con cuatro municipios afectados (Alquife, Aldeire, Jerez del Marquesado y Lanteira), sino también por tratarse del primer expediente realizado por la Dirección General de Bienes Culturales con la tipología de lugar de interés industrial tras la promulgación de la nueva Ley 14/2007 de 26 de noviembre de Patrimonio Histórico de Andalucia, donde se creaban dos nuevas tipologías, la que ahora nos referimos y la de zona patrimonial. Además, como aclara el Decreto, dicho lugar "posee relevantes valores históricos, geológicos, paisajisticos, técnico-industriales y etnológicos, que han derivado en una forma de vida y de trabajo determinadas, configuradores de una identidad colectiva en el territorio. El reconocimiento patrimonial de este conjunto minero supone en buena medida la puesta en valor de una parte fundamental de la historia y del legado minero-industrial andaluz desde su origen hasta nuestros dias".

Si nos adentramos en la historia minera del distrito del Marquesado vemos que fueron los romanos los primeros en explotar los distintos yacimientos minerales situados en la depresión de Guadix. Posteriormente, otros pueblos, visigodos y árabes principalmente, han aprovechado estos recursos. En el periodo nazarí fue Alquife el principal productor de hierro de Al-Andalus, y será en los siglos XIX y XX cuando alcance su estadio álgido, convirtiéndose en el mayor centro productor de hierro de España.

El Bien se compone en la actualidad de dos zonas claramente delimitadas: la primera zona es el coto minero, formado por el conjunto de las minas de Alquife, en cuyas inmediaciones se encuentran diversas instalaciones industriales, cargaderos de mineral, un puente de hierro, dos vias de ferrocarril y el poblado minero de Los Pozos; la segunda zona, ubicada entre los arroyos del Alcázar y el Alhorí, en el término municipal de Jerez del Marquesado, consiste en una central que funcionó como principal medio de abastecimiento de la mina, conocida como la casa de máquinas del salto de agua.

Otro de los expedientes destacable en esta comarca es el denominado Cuenca de Orce, recientemente incoado el procedimiento para su inscripción en el
CGPHA, por Resolución de 26 de julio de 2011 de la Dirección General de Bienes Culturales.

La zona arqueológica de la Cuenca de Orce, situada al noreste de la comarca de Guadix-Baza, contiene un gran número de yacimientos que dan información de primer orden para el conocimiento y compresión del contexto evolutivo de los homínidos fuera del continente africano. En esta área conocida también como la cañada de los Vélez y cañada del Salar, se localizan una serie de yacimientos, de carácter arqueológico y paleontológico que, tanto por la cantidad como por la calidad de su registro, son fundamentales para el conocimiento del Pleistoceno inferior europeo, tratándose de un patrimonio excepcional en el que destacan yacimientos fundamentales para el conocimiento del antes y después de la ocupación humana en el sur de Europa, como Venta Micena, Barranco León o Fuente Nueva 3.

Del mismo modo, encontramos en las comarcas otro tipo de asentamiento humano en abrigos y cuevas que han dejado su huella a través de representaciones de arte rupestre, y en el que destacan dos lugares incluidos en el expediente de Arte Rupestre del Arco Mediterráneo de la Península lbérica, declarado Patrimonio Mundial el 2 de diciembre de 1998: abrigo del los Letreros de los Mártires en Huéscar y cueva de las Grajas en Puebla de Don Fadrique.

El Catálogo General del Patrimonio Histórico Andaluz está abierto a la consulta pública en la página web de la Consejería de Cultura, dentro del área de Bienes Culturales: www.juntadeandalucia.es/cultura

\section{Olga Viñuales Meléndez} Alfonso Montejo Ráez

Servicio de Protección del Patrimonio Histórico Dirección General de Bienes Culturales

\section{Nota}

${ }^{1}$ MIGUEL MORA, C. (2006) La toma de Baza: estrategia militar y politica internacional. Péndulo: papeles de bastitania 7. Granada: Centro de Profesorado de Baza, 2006, pp. 93-108 

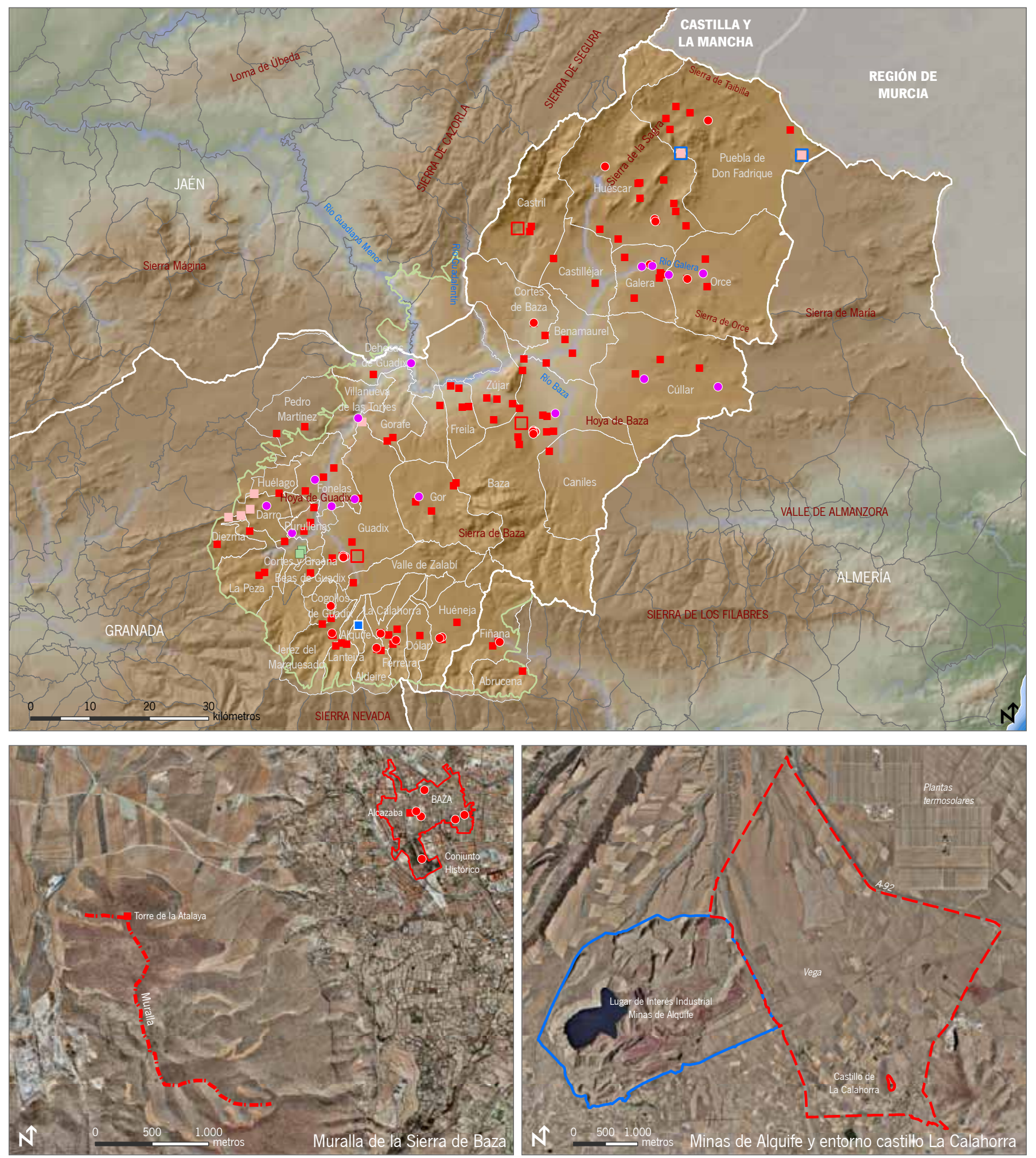

Bien de Interés

Cultural

- Monumento

- Zona Arqueológica

$\square$ Conjunto Histórico

Bien de Catalogación General

Patrimonio Mundial (Unesco)
El Catálogo General del Patrimonio Histórico Andaluz

en las Hoyas de Guadix y Baza

Cartografia base: Datos Espaciales de Andalucia 1:100.000, y Ortofotografia digital en color de Andalucía 1:10.000, Instituto de Cartografía de Andalucía, 2009 